\title{
A ENFERMEIRA COMO CUIDADORA DO SEU FAMILIAR COM DIAGNÓSTICO DE CÂNCER
}

Juliana Balbinot Reis Girondi ${ }^{1}$, Vera Radünz ${ }^{2}$

RESUMO: Trata-se de uma pesquisa qualitativa participante, realizada em 2003, com o objetivo de explorar os significados e vivências das enfermeiras quando as mesmas convivem com o processo de câncer em sua família. Participaram deste estudo quatro enfermeiras. Utilizou-se o Referencial Humanístico de Paterson \& Zderad e de outros autores. Os dados foram obtidos em dois momentos: um de reflexão individual no qual as participantes refletiam sobre algumas questões apresentadas, sob a forma de um roteiro, e um encontro em grupo o qual foi definido como grupo de vivência. Os resultados permitiram analisar os sentimentos das enfermeiras no cuidado ao seu familiar com diagnóstico de câncer, bem como a importância do cuidado humanizado.

PALAVRAS-CHAVE: Cuidados de enfermagem; Neoplasias; Família.

\section{NURSE AS A CAREGIVER OF A FAMILY MEMBER WITH CANCER DIAGNOSIS.}

\begin{abstract}
It is a participant qualitative research, carried through 2003, objectifying: to explore the meanings and experiences of nurses when they go through the cancer process in their own families. Four nurses participated in this study. The Humanistic Reference of Paterson \& Zderad as well as other authors were used. Data were collected in two moments: one of individual reflection in which the participants reflected on some questions presented under the form of a script and a group meeting which was defined as experience group. The obtained results allowed to analyze nurses' feelings when taking care of their own relatives with cancer diagnosis, as well as the importance of qualified and humanized care.
\end{abstract}

KEYWORDS: Nursing care; Neoplasms; Family.

\section{LA ENFERMERA A CARGO DE LOS CUIDADOS DE SU FAMILIAR CON DIAGNÓSTICO DE CÁNCER}

RESUMEN: Se trata de una investigación cualitativa del participante, realizada en 2003 com el objetivo de explorar los significados y las experiencias de las enfermeras cuando las mismas viven el proceso de cáncer en su familia. Participaron de este estudio cuatro enfermeras. El Referencial Humanístico de Paterson y de Zderad fue utilizado y otros autores. Los datos fueron logrados en dos momentos: uno de la reflexión individual, en la cual los participantes reflejaron acerca de algunas preguntas presentadas bajo forma de un guión y de una reunión en el grupo que fue definido como el de experiencia. Los resultados obtenidos permitieron analizar los sentimientos de las enfermeras en el cuidado de sus familiares con diagnóstico de cáncer, así como la importancia del cuidado humanizado. PALABRAS CLAVE: Atención de enfermería; Neoplasias; Familia.

\footnotetext{
${ }^{1}$ Mestre em Enfermagem pela Universidade Federal de Santa Catarina (UFSC). Especialista em Enfermagem Oncológica. Discente da Especialização em Administração Hospitalar Pública pela UFSC. Enfermeira Assistencial da Unidade de Clínica Médica I, do Hospital Universitário - HU Florianópolis. Enfermeira Supervisora em Saúde da Regional Continente de Florianópolis.

${ }^{2}$ Doutora em Enfermagem pela UFSC. Professora do Departamento de Enfermagem da UFSC.
}

Autor correspondente:

Juliana Balbinot Reis Girondi

Rua Delminda Silveira 363, ap. 303 - 88025-500 - Santa Catarina-SC

Recebido em: 03/07/07 Aprovado em: 02/08/07

Cogitare Enferm. 2007 Abr/Jun; 12(2):164-70 


\section{INTRODUÇÃO}

A Enfermagem necessita buscar novos horizontes para sua prática assistencial, descobrir novas formas de perceber o mundo e o próprio processo de cuidar. Em contrapartida, por intermédio da prática, se observa a importância e constata-se a necessidade de novas reflexões acerca do cuidar envolvendo os pacientes com diagnóstico de câncer.

É difícil estar preparado para receber um diagnóstico de câncer. Nesse momento, mais do que nunca, o ser humano percebe que é mortal. É um momento em que crenças são colocadas em cheque, valores são revisados e a vida é revista com um olhar crítico. Distinguir a fantasia entre a doença e a realidade adquire grande importância, porque somente assim será possível lidar com as emoções. Não obstante, não há uma maneira padrão para o enfrentamento desse processo.

Ao considerar o atendimento das necessidades desta clientela, percebe-se a importância do conhecimento, não somente no aspecto biologicista, mas de outras dimensões, incluindo-se as necessidades para a manutenção da existência desses seres humanos. Prosseguindo nesta reflexão, há que se considerar algumas questões: Como os enfermeiros experenciam o processo de câncer quando este é vivenciado em sua própria família? Essa vivência influencia na opção de escolha para atuar nessa área? Durante ou após a vivência deste processo há mudanças na sua postura profissional? De que forma isso afeta os profissionais como seres humanos? $\mathrm{O}$ que leva o enfermeiro oncológico a optar por essa especialização? Estarão os enfermeiros preparados para essas reflexões?

Nesse sentido, acreditamos que os profissionais enfermeiros se deparam com uma situação inusitada, criando, assim, a necessidade de avaliar a sua prática como seres cuidadores, e mais ainda, como seres humanos também necessitados de cuidados. Por conseguinte, diante disso, muitas outras questões passam a ser refletidas. Vislumbra-se certa tendência do enfermeiro a observar e refletir sobre o sensível, o expressivo, e sobre suas responsabilidades, atuação, suas limitações, seu papel e sua prática. Há um novo universo repleto de ações e respostas intersubjetivas que, ao ser conhecido, pode tornar o cuidado realmente centrado na humanização.

Dessa forma, apresenta-se o objetivo deste trabalho: explorar os significados e vivências das enfermeiras quando as mesmas convivem com o processo de câncer em sua família.

\section{METODOLOGIA}

Este é um estudo qualitativo, do tipo participante, em que se utilizou o Referencial Humanístico de Paterson \& Zderad e de outros autores para discussão e análise dos dados. Essa abordagem se afirma no campo da subjetividade e do simbolismo, tendo a palavra como seu material primordial de investigação ${ }^{(1)}$. Foi realizado na cidade de Florianópolis (Santa Catarina), com quatro enfermeiras, algumas atuantes na área oncológica, outras não, que vivenciaram ou vivenciam o processo de câncer em suas famílias. Os dados foram coletados durante a disciplina de prática assistencial do curso de Mestrado em Assistência de Enfermagem da Universidade Federal de Santa Catarina (UFSC), no período de setembro a novembro de 2003. Após a apresentação dos objetivos do estudo, as enfermeiras assinaram o Termo de Consentimento Livre e Esclarecido ${ }^{(2)}$.

Para melhor desenvolvimento da prática, a mesma foi realizada em dois momentos distintos, porém interligados. O primeiro momento foi realizado individualmente, no qual as participantes refletiam sobre algumas questões apresentadas sob a forma de um roteiro. O segundo momento, o qual foi definido como grupo de vivência, trouxe o encontro das participantes para criar um espaço de reflexão e discussão em grupo acerca de questões já elencadas anteriormente, no primeiro momento. Os dois momentos foram guiados pela observação participante, na qual o observador se colocou, aprendendo e vivendo junto com as participantes do estudo $^{(3)}$. Nesse recurso metodológico, as situações não programadas, a capacidade de agir com empatia e a observação por parte do pesquisador enriquecem o estudo $^{(4)}$. Os dados foram obtidos mediante registros no diário de campo e por gravação em fita cassete. Concomitantemente houve a representação da rede de significados dos principais conteúdos expostos sobre o fato de a enfermeira vivenciar o processo de câncer na sua família.

\section{RESULTADOS E DISCUSSÃO}

\section{Relatando a análise do primeiro momento}

Ao iniciar a análise dos dados deste estudo, foram surgindo unidades de significados, as quais originaram categorias e subcategorias, conforme descritas a seguir. 


\section{Ser enfermeiro frente ao processo de câncer}

Ao serem interrogadas sobre como refletem a respeito de ter tido ou ter um familiar com câncer, as enfermeiras fizeram várias colocações, que foram agrupadas nas seguintes subcategorias: Impotência, Cobranças, Alerta, Frustração, Culpa e Ansiedade.

Esses significados nos remetem ao fato de que dificilmente existe outra doença que induza tantos sentimentos negativos em qualquer um dos seus estágios: o choque do diagnóstico, o medo da cirurgia, a incerteza do prognóstico e recorrência, efeitos da radioterapia e quimioterapia adjuvantes, o medo de sofrer dor e de encarar a morte indigna ${ }^{(5)}$. A experiência da doença geralmente se caracteriza pelo medo, pela ansiedade e pela perda. Mas, se as pessoas forem capazes de aprender e evoluir com esse evento, poderão transformálo em uma oportunidade e não em uma infelicidade ${ }^{(6)}$.

\section{Enfrentamentos frente ao processo de câncer}

Ao serem questionadas sobre como lidam com câncer na família e o que significa ter câncer, as enfermeiras fizeram várias colocações as quais foram agrupados nas subcategorias: Desafios, Mudanças e Superação.

Essas questões demonstram que não há uma maneira padrão de enfrentar as reações provocadas pelo câncer. $\mathrm{O}$ significado do momento da vida em que o paciente recebe o diagnóstico difere muito, dependendo de variáveis como a idade e o estado psicológico ${ }^{(7)}$.

\section{Repercussões para a Enfermagem}

Ao serem questionadas sobre a existência de alguma relação entre o fato de vivenciar o processo de câncer em sua família com a escolha e/ou atuação profissional, todas as participantes colocaram que primeiramente passaram pela experiência profissional e após pela experiência familiar. Ao investigar sobre o preparo profissional para cuidar de um paciente oncológico, todas falaram sobre a deficiência deste aprendizado durante a graduação.

Ao serem instigadas a refletir sobre quais aspectos a enfermeira precisa evoluir em relação à prática do cuidado ao paciente oncológico, as participantes colocam que a Enfermagem deve cuidar interagindo com os pacientes no sentido de ajudá-los na adaptação e enfrentamento da realidade, já que esse cuidado humano está contemplado por uma série de valores que, independentemente do enfoque abordado, deverá ter como prioridades o respeito, a liberdade, a comunicação e o amor. Dessa forma, a Enfermagem está apta a ajudar o paciente a recuperar o seu valor como ser humano, independente do processo que está vivenciando, motivando-o para enfrentare superar dificuldades, apesar de algumas limitações. Esse enfoque deve combinar a medicina convencional, o cuidado humano e um apoio psicológico e espiritual. Em alguns momentos, a medicina tecnológica e tradicional negligencia a relação entre corpo, mente e espírito. Isso infelizmente está presente em diversas instituições, nas quais o conhecimento técnico é sobreposto à humanização, quando na verdade estes devem se completar ${ }^{(8)}$.

\section{Relatando a análise do segundo momento}

Nesse momento foi realizado o encontro em grupo das participantes, o qual foi designado grupo de vivência. Como metodologia de trabalho foi feita nova leitura das entrevistas individuais e optou-se por levar para o grande grupo os pontos que tiveram destaque no primeiro momento. Sendo assim, foi escritas em tarjas de papel algumas colocações feitas pelas participantes durante os encontros individuais, referentes aos temas mais abordados, com a sugestão de que durante o encontro cada uma delas retirasse algumas tarjas, aleatoriamente, e as colocasse em debate. As falas selecionadas foram as seguintes:

Sinto-me culpada por não ter descoberto o diagnóstico antes. Eu sou enfermeira, como não percebi isso antes?

A Enfermagem, e também os outros profissionais, tem de ver a pessoa e não só a doença, o tumor. Falta sensibilidade.

Na faculdade eu não aprendi nada sobre Oncologia. Não me considero instrumentalizada para trabalhar.

O câncer é uma doença que serve de alerta de que alguma coisa tem que mudar.

O câncer é uma doença falsa. Eu acho que tem diferença entre o câncer e outras doenças.

Para mim a doença foi um atestado de óbito [...] quando você coloca a palavra câncer é um bicho papão tão grande que você já fica deprimida antes de fazer qualquer tratamento. 


\section{Integrando o primeiro e o segundo momento}

Para entender os significados que surgiram, os dados foram agrupados em categorias, a fim de associar os dois momentos: o primeiro, individual, ao segundo, grupal.

Nas categorias associadas ao ser enfermeiro frente ao processo de câncer apresentou-se uma temática indicativa de imagem negativa e a outra com imagem positiva. As respostas relacionadas com a imagem negativa são mais representativas e evidentes. Nessa temática, o enfermeiro percebe-se impotente, experenciando situações de ansiedade, culpa e frustração, além de perceber as cobranças que permeiam esse contexto. As respostas que ficaram com a temática imagem positiva são menos representativas. Nessa temática, aparece a questão de que o câncer serve como alerta de que são necessárias algumas mudanças de vida, ou seja, compreende um evento que pode acontecer na vida de qualquer pessoa e, que de alguma maneira, serve para levá-las a refletir sobre suas atitudes e seu modo de viver, conforme Figura 1.

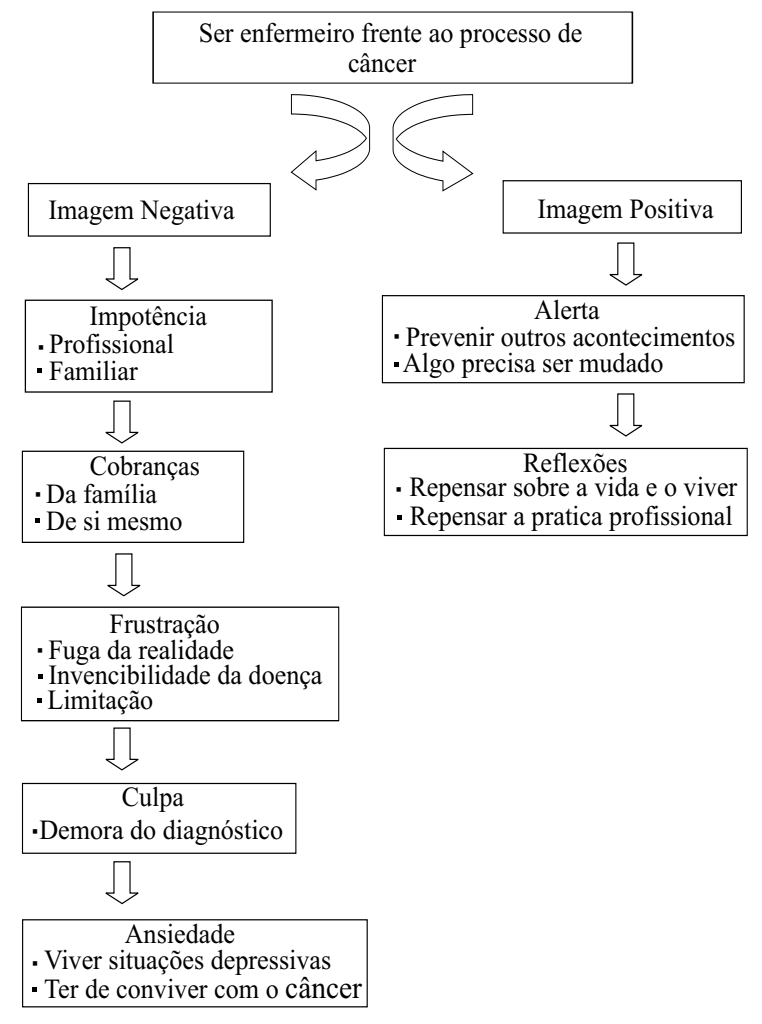

Fonte: Pesquisa de campo

Figura 1: Significados atribuídos ao ser enfermeiro frente ao processo de câncer. Florianópolis, 2003
Todo o processo de conviver com um diagnóstico de câncer transita desde a negação à aceitação, apesar de nem todos experimentarem todos os estágios e estes não seguirem uma mesma ordem de enfrentamento. O fato de ter câncer oportuniza um momento de reflexão na vida das pessoas. As limitações, metas e objetivos são colocados em xeque e avaliados no seu contexto mais amplo, propondo-se obter, a partir daí, nova postura frente à vida.

Há várias situações que limitam a possibilidade do diagnóstico precoce. Isso interfere em vários aspectos durante a evolução da doença. O desconhecimento, por parte dos profissionais da saúde, quanto às possibilidades de remissão no diagnóstico precoce de vários tipos de câncer é uma realidade; o diagnóstico de câncer ainda é enfocado por profissionais como uma única patologia ${ }^{(9)}$.

O cuidado como foco central da Enfermagem demanda energia do cuidador, por isso há a necessidade de reabastecer as energias para que ele e a pessoa cuidada saiam fortalecidos desse encontro. Se não for atingido este equilíbrio, ambos enfrentarão situações de desgaste e estresse constantes e comuns ao processo que está sendo enfrentado. Como conseqüência disso, podem surgir situações de doença também neste cuidador ${ }^{(10)}$.

Nas categorias associadas aos enfrentamentos do enfermeiro frente ao processo do câncer, as temáticas apresentaram-se como enfrentamentos positivos e negativos. As evidências ficaram mais representadas com a temática de enfrentamentos positivos, na qual os enfermeiros incluem respostas relacionadas com as mudanças na visão de mundo deste e de seus familiares, apesar do impacto inicial do diagnóstico ser assustador e desmotivador. Mas, o enfrentamento e a forma de lidar com a doença são capazes de alterar positivamente a trajetória que está por vir. Todas essas formas de enfrentamento favorecem o crescimento integral do enfermeiro como profissional e ser humano. As respostas relacionadas com a temática de enfrentamentos negativos são também representativas. Nesta, o enfermeiro percebe a dificuldade em cuidar do paciente com câncer devido às limitações que a doença e os tratamentos geram, principalmente devido a alguns casos em que não se atinge a cura da doença e se vive situações que possam enfocar o risco de morte iminente. Essa dificuldade não está presente somente quando esse enfermeiro possui 
um familiar com a referida patologia, mas também quando precisa cuidar de outros pacientes na mesma situação. Por isso, o enfermeiro se exime de eventos que podem lembrá-lo daquela experiência que ele já viveu ou que está vivendo, tal como mostra a Figura 2.

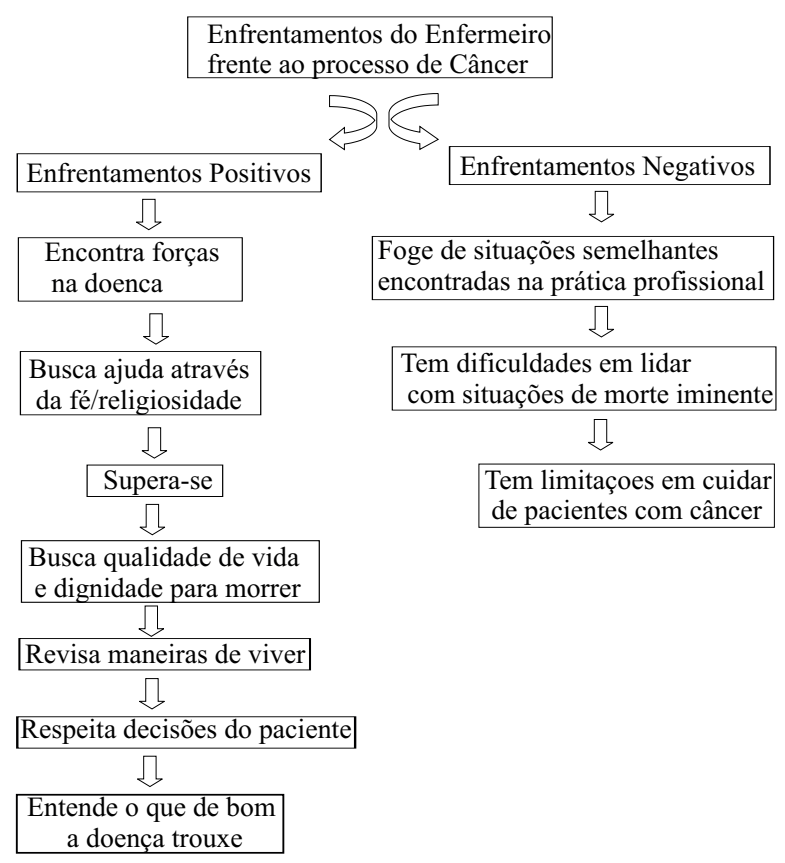

Fonte: Pesquisa de campo

Figura 2 - Significados atribuídos aos enfrentamentos do enfermeiro frente ao processo do câncer. Florianópolis, 2003

O ser que se descobre através da doença e do sofrimento é um ser que se realiza, ser que transforma e se transforma, ser que busca a unidade como experiência interior. É a descoberta de um ser que transmuta através da doença e busca outras possibilidades dentro do processo de ser e viver saudável, apesar da doença e do sofrimento de estar doente ${ }^{(11: 106)}$

A doença pode representar para algumas pessoas um marco, ou seja, um processo no histórico de ser e de viver dessa pessoa. Dessa forma, o câncer passa a ser mais do que uma doença, ele pode ser uma maneira de viver/estar vivo, sendo possível alcançar um equilíbrio dentro das limitações da doença e do processo individual de cada ser.

Se aceitarmos que cada um de nós é potencialmente um transformador de experiência, pode haver uma maneira saudável de se ter uma doença, uma maneira saudável de se enfrentar uma crise. As tragédias e as dificuldades da vida cotidiana podem se tornar uma maneira de saber quem somos e como desejamos viver ${ }^{(6: 102)}$.

Ao longo do curso da doença, o afastamento da pessoa de suas atividades ocupacionais, despersonaliza-a, incutindo efeitos negativos na sua qualidade de vida. Percebe-se que, como enfermeiros, nossas ações ainda estão muito voltadas para o critério de quantidade de dias de vida, sem muitas vezes avaliarmos todo o contexto no qual este paciente está inserido. E, nesse processo, a forma como vemos a morte certamente influenciará no cuidado que ofertamos aos pacientes oncológicos e seus familiares. E essa forma de cuidado pode ser mudada, conforme o desenvolvimento humano ao longo dos tempos, pois se acredita que nesta perspectiva a Enfermagem tem muito a evoluir.

A qualidade da comunicação entre a equipe de saúde e paciente/família, principalmente com a proximidade da morte pode determinar positivamente a tomada de decisões coerentes e apropriadas, contribuindo para criar um ambiente de maior tranqüilidade e colaboração nas ações tomadas ${ }^{(12: 260)}$.

Pela interação de compartilhar, de reconhecer a experiência humana é que ela também pode ser compartilhada, apesar de ser exclusiva a cada um de nós, é somente assim que podemos realmente entrar em uma prática de Enfermagem Humanística ${ }^{(13)}$.

Nas categorias associadas às repercussões para a Enfermagem apresentou-se algumas temáticas em relação ao cuidado de enfermagem ao paciente oncológico: Expansão da profissão e Limitação da profissão. Na temática expansão da profissão, surgem questões sobre a necessidade de adquirir conhecimentos e instrumentalização para cuidar do paciente com câncer, a necessidade do cuidado ser mais humanizado, a abolição de estigmas relacionados ao câncer e a ampliação de percepções como profissão para que possa prestar este tipo de cuidado. Nas temáticas limitações da profissão, surgem questões sobre a falta de conhecimentos e instrumentalização para a prática do cuidado do paciente com câncer, a enfermagem transferindo ações de cuidado ao paciente que não se encontra preparado para assumir essa responsabilidade e o estigma frente ao câncer, que como profissionais as sumimos perante a sociedade, como mostra a Figura 3. 


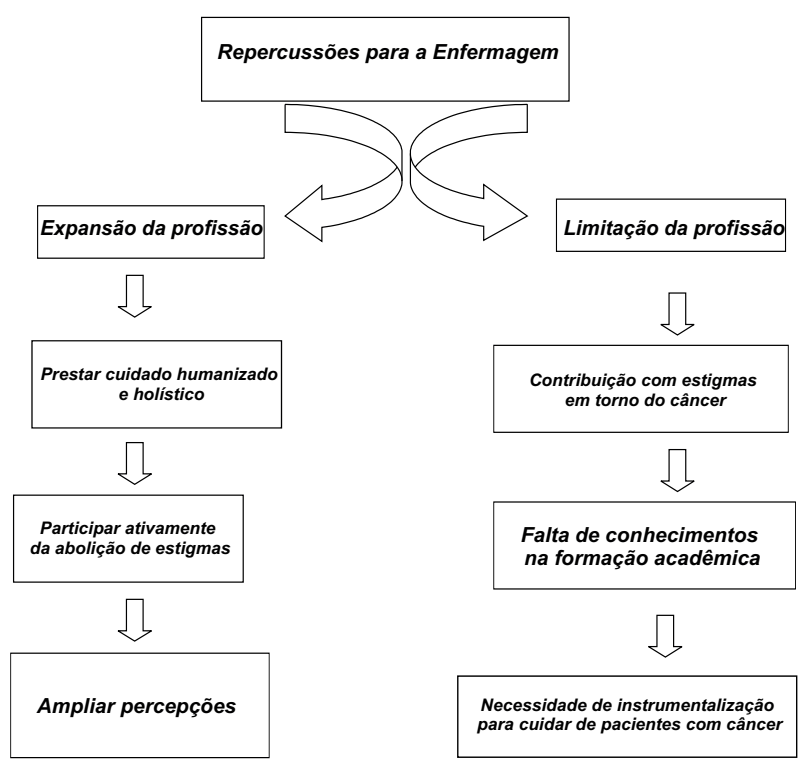

Fonte: Pesquisa de campo

Figura 3 - Significados atribuídos às repercussões para a Enfermagem. Florianópolis, 2003

Para cuidar de pacientes com câncer é necessário que se preste igual atenção a problemas físicos, psíquicos e emocionais. Esse enfoque deve combinar a medicina convencional, o cuidado humano e o apoio psicológico e espiritual ${ }^{(8)}$. Na nossa prática cotidiana, geralmente observamos que o conhecimento técnico é sobreposto à humanização, quando estes devem complementar-se. Assim, o cuidado da Enfermagem deve estar voltado para a qualidade de vida, apesar da doença e da necessidade de repadronizar a saúde do indivíduo e de sua família ${ }^{(14)}$.

Grande parte dessa fragilidade se deve ao fato de que os cursos de graduação no Brasil enfrentam dificuldades no ensino e na assistência de Enfermagem aos pacientes com diagnóstico de câncer ${ }^{(15)}$.

\section{CONSIDERAÇÕES FINAIS}

Dentre as várias constatações que se pode fazer, cabe ressaltar que, embora o câncer seja considerado, universalmente, um evento biológico e temeroso, não há como desconsiderar o contexto em que ele ocorre. Os profissionais e seus familiares sofrem todas as ambigüidades e dúvidas que surgem durante a experiência de conviver com um de seus familiares com essa patologia. Os conhecimentos, as crenças e visões que se têm sobre a doença influenciam o agir dos mesmos.
Os resultados deste trabalho com os enfermeiros direcionaram as reflexões sobre a sua atuação ao vivenciar o processo de câncer na família. Essa vivência também despertou para o fato de que os enfermeiros estão precisando de cuidados. Isso foi representado através de falas, gestos, expressões e, principalmente, pelo silêncio. As reações e ações são diferentes, mas essas necessidades são intensas, possuindo dimensões imensuráveis.

Finalizando, acreditomos que um dos maiores desafios para a Enfermagem é a desmistificação do 'problema-câncer', interferindo na realidade, especialmente em relação à prática do cuidado do paciente com esse diagnóstico. $\mathrm{O}$ enfermeiro deve atuar de forma a garantir a esse paciente condições dignas e humanas, ajudando-o no enfrentamento e respeitando suas formas de lidar com esse processo em sua vida. É compromisso nosso interferir nesta realidade -"de que nada pode ser feito"- apontando para o fato de que há muitas formas de cuidar de um paciente com diagnóstico de câncer.

\section{REFERÊNCIAS}

1 Minayo MSC, Sanches O. Quantitativo-qualitativo: oposição ou complementariedade? Cad Saúde Públ. 1993 Jul/Set;(9):237.

2 Brasil. Resolução n. 196, de 10 de outubro de 1996. Dispõe sobre diretrizes sobre pesquisas que envolvem seres humanos. Resolução CNS 196/96. Disponível em: http://conselho.saude.gov.br/comissao/conep/ resolucao.html (07 Jul 2007).

3 Minayo MCS. O desafio do conhecimento: pesquisa qualitativa em saúde. $6^{\mathrm{a}}$ ed. São Paulo: Hucitec; 1998.

4 Rubin HJ, Rubin IS. Qualitative interviewing: the art of hearing data. Londres: Sage; 1995.

5 Deitos F, Gaspary JFP. Estresse, câncer e imunidade. Santa Maria: Kaza do Zé; 1997.

6 Remen RN. O paciente como ser humano. São Paulo: Summus; 1993.

7 Murad AM, Katz, A. Oncologia: bases clínicas do tratamento. Rio de Janeiro: Guanabara Koogan AS; 1996.

8 Simonton C. Com a vida de novo. São Paulo: Summus; 1987.

9 Marcelini, SMR. Cuidado domiciliar: reflexões sobre a convivência entre enfermeira, cuidador domiciliar e portadores de câncer avançado [dissertação]. 
Florianópolis (SC); Universidade Federal de Santa Catarina; 2000.

10 Souza AIJ, Radünz,V. O cuidado na hospitalização: uma perspectiva infanto-juvenil. Texto Contexto Enferm.1998 Mai/Ago;7:195-218.

14 Parse, RR. Man-living healtth: a theory of nursing. New York: Weley; 1981.

15 Gutierrez, MGR. O ensino de cancerologia nos cursos de graduação em Enfermagem: porque e para quê? Rev Bras Cancerol. 1993;39(1):11-20. 